\title{
Acupuncture blocks cold stress-induced increases in the hypothalamus-pituitary-adrenal axis in the rat
}

\section{Ladan Eshkevari, Eva Permaul' and Susan E Mulroney ${ }^{2}$}

School of Nursing and Health Studies, Georgetown University Medical Center, 421 St Mary's Hall, 3700 Reservoir Road NW, Washington, District of Columbia 20007, USA

Departments of ${ }^{1}$ Histopathology and ${ }^{2}$ Pharmacology and Physiology, Georgetown University Medical Center, Washington, District of Columbia 20007, USA

\section{Correspondence}

should be addressed

to L Eshkevari

Email

eshkevl@georgetown.edu

\begin{abstract}
Electroacupuncture (EA) is used to treat chronic stress; however, its mechanism(s) of action in allaying stress remains unclear. The interplay of stress hormones of the hypothalamuspituitary-adrenal axis (HPA) and the sympathetic nervous system (SNS) is critical in the stress response. Our objective was to determine whether EA at acupoint, stomach $36\left(\mathrm{EA} \mathrm{St}_{36}\right)$ is effective in preventing chronic cold stress-induced increased hormone levels in the rat by examining four groups of animals, three of which were exposed to cold and one of which was a non-treatment control group. Before exposure to the cold, two groups were treated with either EA St ${ }_{36}$, or Sham-EA, before 10 days of cold stress. The EA St $\mathrm{S}_{36}$ animals demonstrated a significant decrease in peripheral HP hormones (ACTH and CORT) compared with stress animals $(P<0.05)$. These effects were specific; rats receiving Sham-EA had elevation of these hormones, similar to the stress-only animals. These effects were mirrored centrally in the brain; $\mathrm{CRH}$ levels were significantly $(P<0.05)$ reduced in EA St $\mathrm{St}_{36}$ animals compared with the other animals. Finally, EA effect on peripheral and adrenal SNS hormones (norepinephrine (NE) and neuropeptide Y (NPY) respectively) was examined, with no significant difference noted in adrenal tyrosine hydroxylase or circulating NE in any of the groups. However, EA St ${ }_{36}$ was effective in preventing stress-induced elevation is adrenal Npy mRNA. These results indicate that EA St ${ }_{36}$ blocks the chronic stress-induced elevations in the HPA and the sympathetic NPY pathway, which may be a mechanism for its specific stress-allaying effects.
\end{abstract} Key Words

\section{Introduction}

The classic response to chronic stress consists of an elegant, concerted interplay of two important pathways, the sympathetic nervous system (SNS) and the hypothalamus-pituitary-adrenal axis (HPA). The chronic activation of these stress pathways can lead to maladaptive homeostatic conditions causing symptoms or diseases http://joe.endocrinology-journals.org DOI: 10.1530/JOE-12-0404
(C) 2013 Society for Endocrinology Printed in Great Britain such as depression, anxiety, and obesity, which may have a direct impact on cardiovascular disorders and hypertension (Szczepanska-Sadowska et al. 2010, Tamashiro 2011, Tamashiro et al. 2011, Tran et al. 2011, McEwen 2012, McEwen et al. 2012). The initial response to stress consists of an increase in the central expression of numerous 
catecholamines and peptides in the sympathetic ganglia such as norepinephrine (NE) and neuropeptide Y (NPY) (Nankova et al. 1996, Bernet et al. 1998). NPY and NE have been found to cross talk with the HPA in the CNS causing release of CRH. However, in chronic stress while NE levels return to normal, NPY levels remain elevated, thereby playing a modulating role in NE release in chronic stress (Renshaw et al. 2000, Cavadas et al. 2001, Heilig 2004). As such, NPY plays a cost-saving role for NE, so it can be reserved for more acute responses, during times of chronic stress. Concomitantly, the increase in hypothalamic $\mathrm{CRH}$ stimulates the release of ACTH from the pituitary gland. This leads to a subsequent release of corticosteroids as well as NE and epinephrine from the adrenal glands.

Indeed, the HPA and SNS are anatomically and functionally unified; during stress, they interact both in the periphery and in the CNS (Li et al. 2000, Jacobson 2005, Dimitrov et al. 2007, Kakui \& Kitamura 2007). The hypothalamic paraventricular nucleus (PVN) is a major site for direct neuronal NPY and NE input to CRH cell bodies (Suda et al. 1993, Li et al. 2000). In several rodent models of chronic stress, such as cold stress, the increase in PVN NPY leads to stimulation of CRH synthesis and subsequent increase in serum corticosterone (CORT) levels (Jacobson 2005, Kakui \& Kitamura 2007). It has also been observed that injection of NPY into the PVN increases circulating ACTH and CORT, while ACTH has been demonstrated to exert modulating influences on adrenal NPY (Suda et al. 1993, Hinson et al. 1998).

Given the negative physiological impact of chronic stress, blocking the stress-induced effects of the SNS and HPA may provide a much needed protection against stressrelated disorders. Acupuncture has been widely used for over 2500 years across Asia and has most recently gained popularity in Western cultures. Traditional Chinese Medicine (TCM) practitioners have traditionally used electroacupuncture (EA) in the treatment of stress-related disorders; however, there has been little evidence to support its efficacy as an anxiolytic. Two studies have shown that acupuncture can block acute stress-induced increases in the HPA axis (Han et al. 1999, Yang et al. 2002). Although there is limited information on chronic stress, we have recently reported that EA at acupoint Zusanli, stomach $36\left(\mathrm{St}_{36}\right)$ can ameliorate chronic cold stressinduced increases in central (PVN) and peripheral (plasma) NPY in rats, providing one potential mechanism of action of acupuncture on reducing stress (Eshkevari et al. 2012).

The objective of the current study was to determine whether application of $\mathrm{EA}$ at $\mathrm{St}_{36}\left(\mathrm{EA} \mathrm{St}_{36}\right)$ during chronic cold stress blocks the stress-induced increases in the major hormones of the HPA and how changes may be related to the adrenal SNS response. This model of chronic stress has been well established by others in our department; Kuo et al. (2007) used this model to study the role of NPY in the relationship between stress and obesity (Kuo et al. 2007). We therefore used this chronic stress/pain paradigm to examine PVN CRH, adrenal NE and NPY, and circulating CORT and ACTH in sham and $\mathrm{EA} \mathrm{St}_{36}$ rats after 10 days of cold stress. We chose $\mathrm{ST}_{36}$ because it is a potent point on the human meridian point system according to TCM. It is used in many instances in TCM, including stress.

\section{Materials and methods}

\section{Animals}

The animal experiments in this study were approved by the Georgetown University Animal Care and Use Committee (GUACUC), in compliance with National Institute of Health guidelines. A total of 34 adult male Sprague Dawley rats weighing 290-420 g, with indwelling jugular catheters, were received from Harlan Laboratories, Inc. (Dublin, VA, USA). The rats were randomly assigned to four groups. Groups 1 and 2 were controls $(n=7$ per group): group 1 received no treatments (Control group), while group 2 was the stress-only (Stress) group in which the animals were exposed to 10 days of cold stress. The two experimental groups ( $n=10$ per group) consisted of a sham EA group (Sham-EA), which received 4 days of pretreatment with EA at a sham point $5 \mathrm{~mm}$ away from the rat tail, bilaterally with no stress, followed by Sham-EA for the next 10 days immediately preceding exposure to the cold stress; the fourth group was the experimental EA group, which was pre-treated with $\mathrm{EA} \mathrm{St}_{36}$ for 4 days before the cold stress and continued to receive $\mathrm{EA} \mathrm{St}_{36}$ immediately before exposure to the cold stress for 10 additional days. EA St ${ }_{36}$ was specifically used, not only because of its efficacy to manage stress according to TCM but also due to its location (Fig. 1). $\mathrm{St}_{36}$ is located $0.5 \mathrm{~cm}$ below fibular head of the hind leg in rat bilaterally and is easily acupunctured while the rat remains conscious. It was important to conduct the acupuncture on non-anesthetized animals in our study, given the confounding known effects of anesthetics on stress hormones.

The rats were housed one per cage, to protect the jugular catheters, and the room was kept at a constant temperature of $23{ }^{\circ} \mathrm{C}$. The jugular catheters were checked on the day of arrival. Catheter care that consisted of ensuring patency with a $1 \mathrm{cc}$ sterile syringe and a $23 \mathrm{G}$ blunt tip sterile stainless steel needle (Small Parts, Inc.,

Published by Bioscientifica Ltd

Downloaded from Bioscientifica.com at $04 / 26 / 2023$ 11:39:16AM 
Seattle, WA, USA), followed by injection of $0.1 \mathrm{ml}$ of the Harlan recommended lock solution: $5 \mathrm{ml}$ 100\% sterile glycerin (Fisher Scientific, Pittsburg, PA, USA) with $5 \mathrm{ml} 1000 \mathrm{U} / \mathrm{ml}$ heparin sodium, was performed on days 1 and 7 of the experiment. The animals were maintained in a $12 \mathrm{~h}$ light: $12 \mathrm{~h}$ darkness cycle with free access to food and water. All animals were familiarized with the experiment personnel for 4 days before the onset of the experiments by petting the animals and allowing them to crawl into a cotton sock, which was later used in the protocol to momentarily hold the animal in place while inserting acupuncture needles. The control animals (Control) received no further treatments once the experiment was begun, while the stress control group received only cold stress.

\section{Acupuncture}

The acupuncture protocol consisted of placing the animal; head first, into the cotton sock previously used in the acclimation period. Once the animals were comfortably secured in the sock, sterile, stainless steel, single-use acupuncture needles measuring $34 \mathrm{G}(0.22 \mathrm{~mm})$ and 1 inch $(25 \mathrm{~mm})$ (Millennia, Shanghai, China) were quickly inserted either in the Sham point or the $\mathrm{EA} \mathrm{St}_{36}$ point, bilaterally. The electrodes were wrapped quickly around the needle and were taped in place to the needle and then to the rat. The electrodes were subsequently attached to an EA machine (Model AWQ-104L, UPC Medical Supplies, San Gabriel, CA, USA). The animals were placed in a single cage on bedding material and did not receive food or water for the duration of the treatment, which lasted for $20 \mathrm{~min}$. The points were stimulated at a frequency of $10 \mathrm{~Hz}$ with $2 \mathrm{~mA}$ output, and a pulse width of $0.1 \mathrm{~s}$, based on other rat models of acupuncture treatment (Lao et al. 2004, Zhang et al. 2005). The uniformity of the electrical output was achieved using an oscillometer that measured the EA machine's outputs on all rats and adjusted to achieve the desired output. All acupuncture treatments occurred in the morning between 0900 and $1100 \mathrm{~h}$ and were administered $30 \mathrm{~min}$ before the initiation of the cold stress treatments, and animals were observed closely to ensure that needles were not displaced.

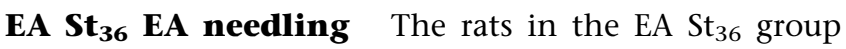
received EA treatments as described earlier. The location of the needles for EA St ${ }_{36}$ is on bilateral hind legs of the animal. These points were identified using rat mapping for TCM acupuncture. We chose $\mathrm{St}_{36}$ as the TCM acupoint of interest as it is considered one of the most potent and commonly used points in TCM practice. Additionally, previous rodent stress studies have successfully demonstrated that $\mathrm{St}_{36}$ can modulate stress pathways (Lim et al. 2003, Sun et al. 2005, Eshkevari et al. 2012).

Sham-EA needling EA treatment for the sham group was the same as described earlier, except the points selected were non-acupuncture map points on the back of the animal, $2 \mathrm{~cm}$ lateral to the tail region. This point was used as the sham point as there are no known acupuncture points near them and they were out of reach of the animals.

\section{Stress}

On day 4 of the experiment, cold stress, which entailed placing the animal in $1 \mathrm{~cm}$ deep crushed ice $\left(2-5^{\circ} \mathrm{C}\right)$ for $1 \mathrm{~h}$ daily, was carried out as described previously (ZukowskaGrojec 1995). The stress, Sham-EA and EA St ${ }_{36}$ animals received this daily 1 -h cold exposure for 10 days. The animals in the Sham-EA and EA $\mathrm{St}_{36}$ were placed in the cold stress cages $30 \mathrm{~min}$ after they had received their acupuncture treatments. Following the cold stress, animals were returned to their home cages and allowed to rest.

\section{Blood sampling}

Blood samples were collected on day 1 (before initiation of any treatments), day 7 , and day 14 of the experiment via the indwelling jugular catheters using a $1 \mathrm{cc}$ sterile syringe. Following blood collection, the sterile heparin lock solution was replaced and animals were returned to their cages. On days 7 and 14 of the protocol, the animals were exposed to the acupuncture and cold stress treatments and allowed to acclimate to room temperature (RT) for $1 \mathrm{~h}$ before bloods were drawn between 1100 and $1300 \mathrm{~h}$. The blood sampling occurred between these times taking into account the diurnal nature and circadian fluctuations of ACTH and CORT. Plasma was collected in $1.5 \mathrm{ml}$ EDTA tubes, centrifuged at $4{ }^{\circ} \mathrm{C}$ at $6708 \boldsymbol{g}$ for $2 \mathrm{~min}$, and the supernatant plasma was stored at $-80^{\circ} \mathrm{C}$. Serum was collected in $1.5 \mathrm{ml}$ low retention tubes, placed on a rack at RT for $15 \mathrm{~min}$, and centrifuged at RT for $5 \mathrm{~min}$ at 5000 r.p.m. The supernatant serum samples were collected and stored at $-80^{\circ} \mathrm{C}$.

\section{Analysis of ACTH, CORT, and NE by ELISA}

Each ELISA was performed in accordance with the manufacturer's recommended protocols. ACTH ELISA was performed using an ELISA kit (Cat \#S-1185; Bachem,

Published by Bioscientifica Ltd 

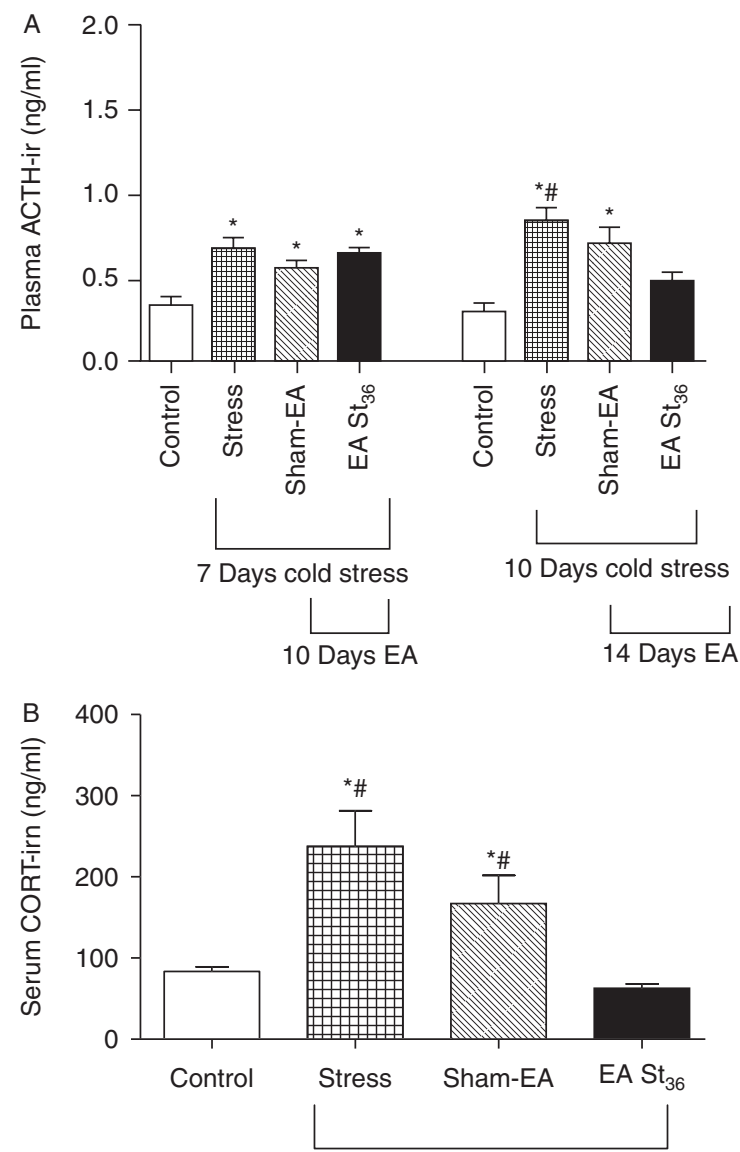

10 Days cold stress
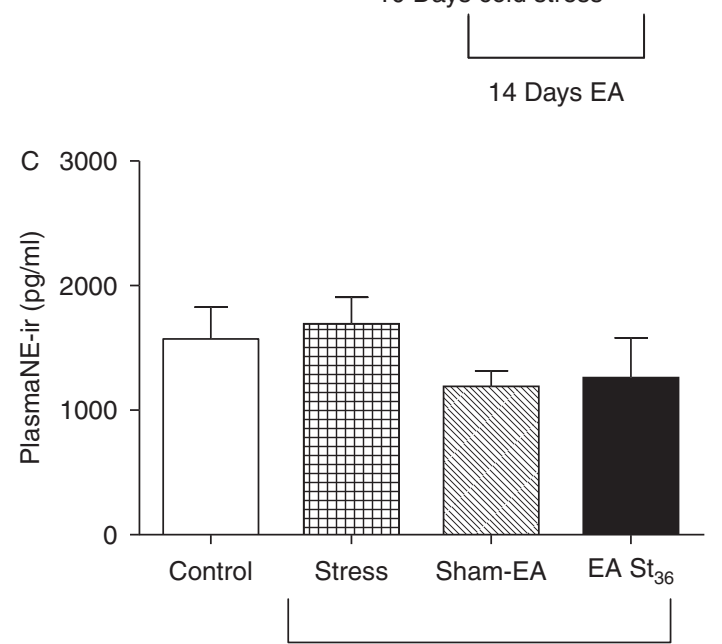

10 Days cold stress

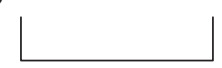

14 Days EA

http://joe.endocrinology-journals.org DOI: 10.1530/JOE-12-0404

() 2013 Society for Endocrinology Printed in Great Britain
San Carlos, CA, USA - specificity of $100 \%$ for rat ACTH with a typical sensitivity of $0.26 \mathrm{ng} / \mathrm{ml}$ ). This kit required an initial extraction step that consisted of equilibrating a $200 \mathrm{mg}$ C-18 sep-column with $1 \mathrm{ml}$ 100\% acetonitrile, followed by $1 \%$ trifluoroacetic acid (HPLC grade) $3 \mathrm{ml}$, three times, and centrifuged with a cold vacuum centrifuge once it was buffered. The collected residue was rehydrated with equal volume (150 $\mu \mathrm{l})$ of assay buffer, and used in the assay. CORT was determined using an ELISA kit (Cat \#DSL10-81100 with a specificity of $100 \%$ for rat CORT and a typical sensitivity of $1.6 \mathrm{ng} / \mathrm{ml}$ ) from Diagnostic Systems Laboratories (Webster, TX, USA). NE ELISA kit (Cat \#BA E-5200; Rocky Mountain Diagnostics, Colorado Springs, CO, USA - specificity of $100 \%$ for rat NE with a typical sensitivity of $0.2 \mathrm{ng} / \mathrm{ml}$ ) was used to measure NE.

The optical density from each assay was read on a standard ELISA plate reader set at $450 \mathrm{~nm}$.

\section{Immunohistochemistry}

Immunohistochemical staining for $\mathrm{CRH}$ was performed on formalin-fixed paraffin-embedded $5 \mu \mathrm{m}$ sections of rat brain PVN. As previously published, by Eshkevari et al. (2012), the PVN was located from dorsa-ventral coordinate of $8.0 \mathrm{~mm}$ from Bregma and medio-lateral coordinate of $0.7 \mathrm{~mm}$. The sections were deparaffinized with xylenes and rehydrated through a graded alcohol series, starting with $100 \%$ EtOH and ending with $70 \% \mathrm{EtOH}$, followed by rinsing in water and TBS with $0.05 \%$ Tween. For antigen retrieval, slides were immersed in $10 \mathrm{mM}$ citrate buffer (pH 6.0) with $0.05 \%$ Tween at $98{ }^{\circ} \mathrm{C}$ for $20 \mathrm{~min}$ and allowed to cool for $20 \mathrm{~min}$ at RT. After blocking with $3 \%$ hydrogen peroxidase and 10\% normal goat serum, slides were incubated with a primary antibody, CRH

\section{Figure 1}

( $A$ and $B$ ) Effect of EA given before and concomitantly with chronic cold stress on HPA hormones. (A) Plasma ACTH levels: on day 7, all three experimental groups had significantly higher ACTH levels than the control group ( ${ }^{*} P<0.05$ ). However, by day 14 , plasma ACTH levels in the stress-only and the stress + Sham-EA animals were significantly higher than the control animals $(* P<0.05)$. In sharp contrast, EA St ${ }_{36}$ prevented this increase when compared with the stress-only animals $\left({ }^{\#} P<0.05\right)$. Furthermore, there was no significant difference between the ACTH plasma levels of the $\mathrm{ST}_{36}$ animal compared with the controls. (B) Serum CORT levels: The serum CORT levels in the stress-only and Sham-EA animals were again significantly elevated when compared with control animals $(* P<0.05)$. EA St 36 prevented this elevation when compared with the stress-only and stress + Sham-EA serum CORT levels ( ${ }^{\#} P<0.05$ ). EA St ${ }_{36}$ had effectively prevented the stress-induced increases in serum CORT to levels similar to the control animals. (C) Plasma NE levels: there were no significant differences noted in the plasma NE levels of the four study groups.

Published by Bioscientifica Ltd. 
(1:2000, Abcam ab8901, Cambridge, MA, USA) for $1 \mathrm{~h}$ at RT. HRP-conjugated anti-rabbit secondary antibody (Dako Envision-Plus, San Antonio, TX, USA) was applied for $30 \mathrm{~min}$, and the HRP was detected using DAB chromagen (Dako). Slides were counterstained with hematoxylin (Harris modified hematoxylin; Fisher Scientific) at a 1:17 dilution for $2 \mathrm{~min}$ at RT, blued in $1 \%$ ammonium hydroxide for $1 \mathrm{~min}$ at RT, dehydrated, and mounted with Acrymount. Negative controls consisted of similarly treated consecutive brain sections with the omission of the primary antibody. Slides were visualized using the CRi Nuance FX microscope (Caliper Life Sciences, Hopkinton, MA, USA). The PVN was identified referring to the rat brain map (Paxionos \& Watson 1998). Images $(10 \times)$ were saved using the CRi Nuance v2.6.0 camera and were semi-quantitatively analyzed for positive CRH staining by the MDS Analytical Technologies Metamorph v7.5.5.0 (Sunnyvale, CA, USA).

\section{Quantitative real-time RT-PCR}

Quantitative real-time RT-PCR was used to determine PVN Crh mRNA expression as well as adrenal tyrosine hydroxylase (TH) and Npy mRNA expression. Briefly, total RNA was isolated from resected brain paraventricular nuclei using the previously described phenol-chloroform extraction method (Chomczynski \& Sacchi 1987). One microgram of RNA per sample was used for cDNA synthesis via the iScript cDNA synthesis kit (Bio-Rad). Real-time RT-PCR was done using ICycler iQ Detection System (Bio-Rad). The PCRs were carried out using TaqMan Universal PCR Master Mix and predesigned primers and fluorescein-labeled probes (Applied Biosystems). GAPDH: 5'-CCTTCATTGACCTCAACTAC-3', 5'-GGAAGGCCATGCCAGTGAGC-3'; CRH: 5'-CAA TCG AGC TGT CAA GAG AGC-3', 5'-GGA AGA AAT CCA AGG GCT GAG-3'; $\beta$-actin: $5^{\prime}$-GTG ACG TCC GTA AA-3', 5'-CTC AGG AGG AGC AAT GAT CTC-3'; TH: 5'-GCC ATG AGC TGT TGG GAC AT-3', 5'-CCC CAG AGA TGC AAG TCC AAT-3'; and NPY: 5'-CAG AGG CGC CCA GAG CAG-3', 5'-CAG CCC CAT TCG TTT GTT ACC- $3^{\prime}$. The results were calculated by the comparative cycle threshold (CT) method using GAPDH for the brain, and $\beta$-actin for the adrenals as the endogenous reference genes, per the Applied Biosystems ABI PRISM 7700 User Bulletin \#2.

\section{Statistical analysis}

Data were analyzed using GraphPad Prism v4 (GraphPad Software, La Jolla, CA, USA) and are presented as mean \pm S.E.M. We used one-way ANOVA with Tukey multiple $t$-test or
Kruskal-Wallis post-test depending on the sample size to compare between treatment groups. $P<0.05$ was considered statistically significant for the indicated sample size per group.

\section{Results}

\section{Effect of EA St $t_{36}$ on plasma ACTH and serum CORT in chronically stressed rats}

There were no significant variances in any parameters after 7 days of cold stress among the experimental groups, with ACTH and CORT being elevated similarly in all three cold stress-exposed groups (Fig. 1A). However, after 10 days of cold stress, ACTH and CORT levels in stress-only and Sham-EA animals were significantly $(P<0.05)$ increased compared with the control group (Fig. $1 \mathrm{~A}$ and $\mathrm{B}$ ). In marked contrast, 4 days of pretreatment with $\mathrm{EA}$ at acupuncture point $\mathrm{St}_{36}$ (which continued for 10 days with concomitant exposure to cold stress), ameliorated the effects of cold stress: ACTH and CORT levels in stressed $\mathrm{EA} \mathrm{St}_{36}$ rats were not different from those seen in control animals and were also significantly lower than those of the stress-only and Sham-EA groups $(P<0.05)$ (Fig. $1 \mathrm{~A}$ and $\mathrm{B})$.

\section{Effect of EA St ${ }_{36}$ on plasma NE in chronically stressed rats}

After 10 days of chronic cold stress, there were no significant differences in the plasma NE levels between any groups (Fig. 1C), which was not unexpected, considering changes in circulating NE may be related to more acute stress situations.

\section{Effects of EA St ${ }_{36}$ on PVN CRH}

Figure 2 illustrates PVN Crh mRNA expression. Chronic exposure to cold stress resulted in significant increases in CRH message in stress-only rats and Sham-EA rats when compared with control animals $(P<0.05)$. Although there was no significant difference between $\mathrm{EA} \mathrm{St}_{36}$ and control CRH expression, PVN CRH in the $\mathrm{EA} \mathrm{St}_{36}$ group was also not significantly lower than the other two stress groups. (Fig. 2). A representative immunohistochemistry (IHC) identifying CRH protein in the different groups is shown in Fig. 3A. Figure 3B shows the average number of $\mathrm{CRH}$-positive cells from each group. Stress significantly elevated CRH protein in the PVN compared with control animals $(P<0.01)$. Sham-EA did not prevent the increase; by contrast, $\mathrm{CRH}$ protein in $\mathrm{EA} \mathrm{St}_{36}$ rats was not

Published by Bioscientifica Ltd. 
significantly different from unstressed controls, consistent with its effects on Crh mRNA, but was significantly $(P<0.05)$ lower than the stress-only and Sham-EA animals.

\section{Effects of EA St ${ }_{36}$ on adrenal NPY and TH}

To start identifying how chronic stress-related changes in NE and NPY might relate to the HPA response, we studied the effects of cold stress on the adrenal medullary NPY and TH message (an important enzyme in the synthesis pathway of the catecholamines). We found that chronic cold stress had a significant impact on adrenal Npy mRNA expression in raising transcription activity when compared with the non-stressed control group $(P<0.05$; Fig. $4 \mathrm{~A})$. $\mathrm{EA} \mathrm{St}_{36}$ prevented this significant $(P<0.05)$ increase in message, and levels were similar to that of the control animals. Again, the Sham-EA had failed to prevent the stress-induced increase in NPY (Fig. 4A).

Unlike the stress-induced changes observed in Npy mRNA, there was no change in TH mRNA levels in any of the experimental groups (Fig. 4B). This may again relate to the fact that NE plays a more important role in the acute response to stress while NPY exerts a more chronic effect on modulating NE and maintaining homeostasis in the face of chronic stress.

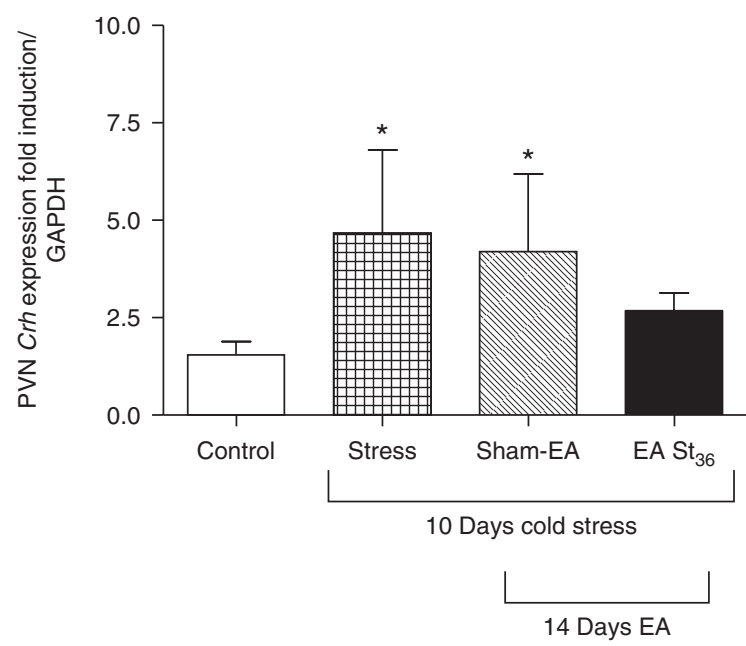

Figure 2

Effect of EA on CRH message in the PVN of chronically stressed rats. Crh mRNA (normalized by GAPDH) was significantly higher in the stress-only and stress + Sham-EA animals when compared with the control animals $\left({ }^{*} P<0.05\right)$. Conversely, this was not observed when evaluating the $C r h$ mRNA levels of the EA St ${ }_{36}$ group to that of the control animals.
A
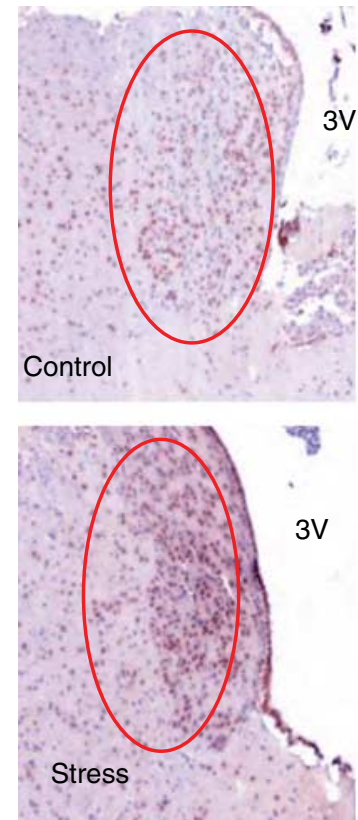

Magnification 10x
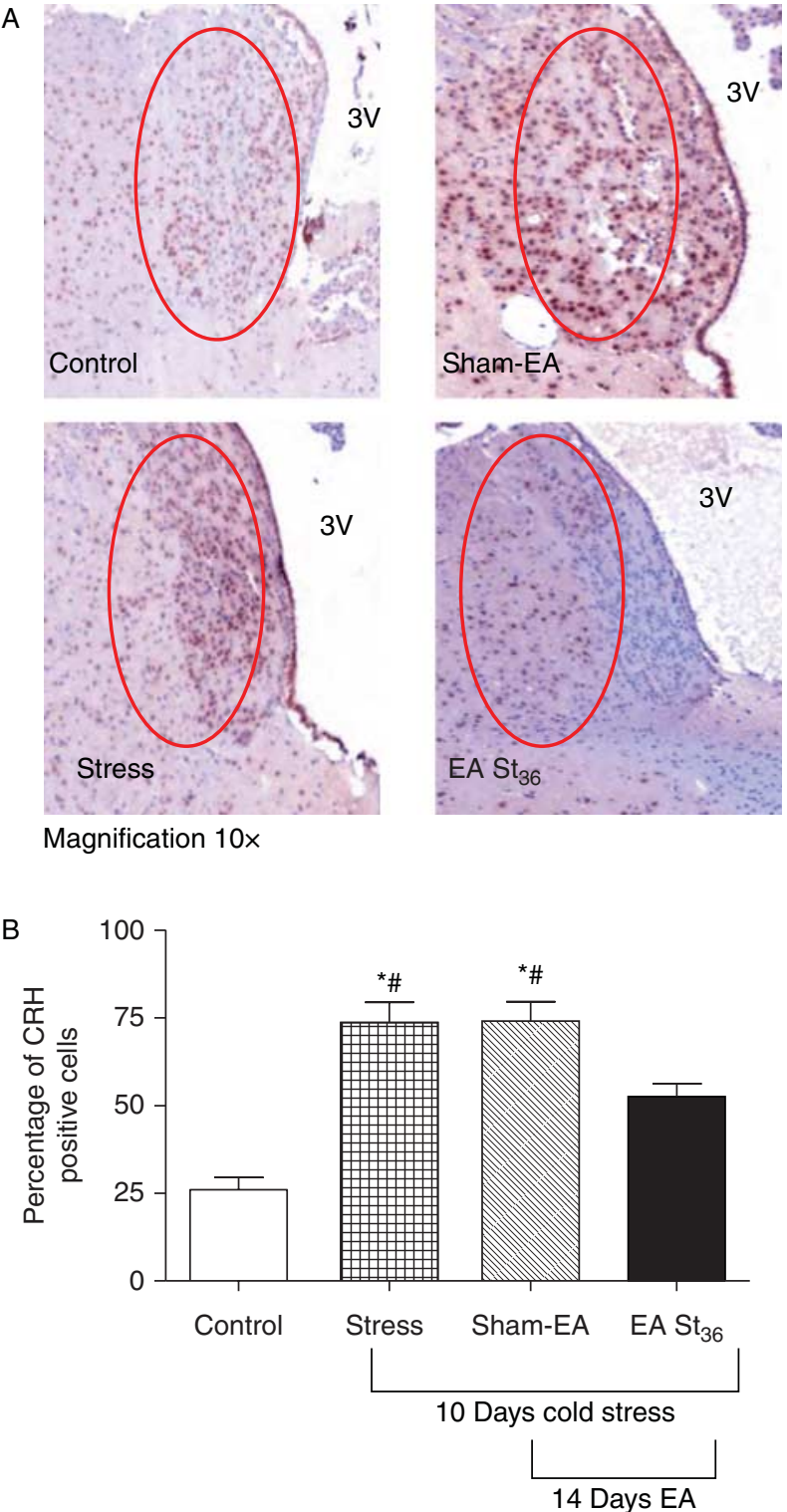

Figure 3

(A and B) Effect of EA on CRH protein expression in the PVN of chronically stressed rats. CRH immunoreactivity was significantly higher in the stress-only and the stress + Sham-EA animals when compared with the control group $\left({ }^{*} P<0.01\right)$. EA St 36 prevented this increase $\left({ }^{\#} P<0.05\right) .3 \mathrm{~V}, 3$ rd ventricle.

\section{Discussion}

Our findings indicate that $\mathrm{EA} \mathrm{St}_{36}$, beginning 4 days before induction of cold stress, can prevent the chronic stressinduced increases in the HPA, as well as SNS-related adrenal NPY. This effect was specific to $\mathrm{St}_{36}$, as Sham-EA was not different to responses in stress-only animals. These findings indicate that the mechanism of action of $\mathrm{EA} \mathrm{St}_{36}$ involves blocking the HPA at (or before) the level of

Published by Bioscientifica Ltd. 

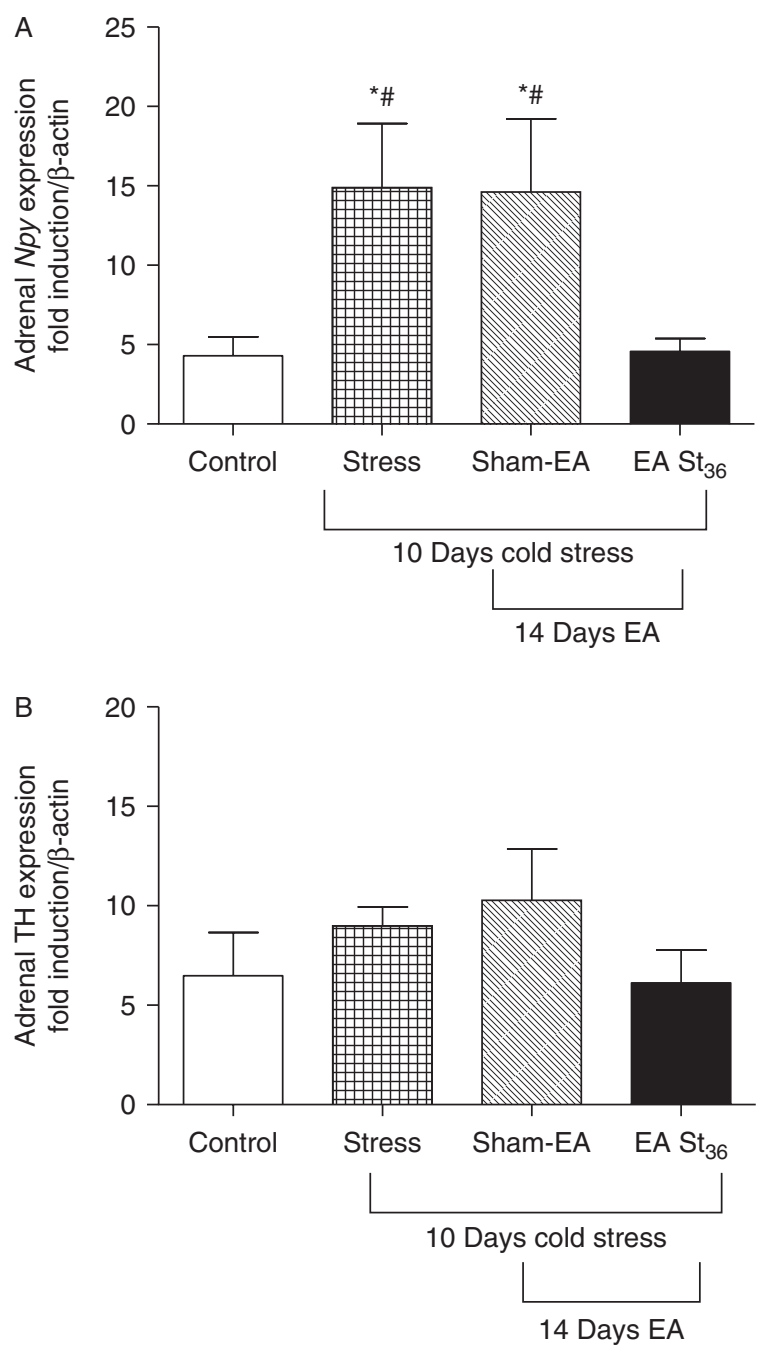

Figure 4

(A and B) Effect of EA on adrenal NPY and TH expression. (A) Adrenal NPY levels: adrenal NPY levels of the stress-only and stress + Sham-EA animals were significantly higher than those of the control animals $(* P<0.05)$. By contrast, EA St 36 prevented this increase $(" P<0.05)$ such that $N p y$ mRNA was similar to that of the control animals. (B) Adrenal TH expression: there were no significant variations noted in the adrenal $\mathrm{TH}$ expression when comparing groups.

PVN CRH. This supports our initial report of the efficacy of EA St $_{36}$ in preventing chronic cold stress-induced increases in central and peripheral NPY (Eshkevari et al. 2012) and extends the information by reporting for the first time that EA ameliorates the effects of chronic stress on the HPA. These findings support targeted EA as therapeutic intervention in chronic stress conditions.

The phenomenon that EA could prevent elevations in ACTH levels in chronic stress was demonstrated in the late 1970s and early 1980s in rat and human models of chronic stress such as opioid withdrawal (Wen et al. 1978, Fung et al. 1980). Our results support and extend these earlier findings in human models of stress. Indeed, pretreatment with EA at TCM point $\mathrm{St}_{36}$ (Fig. 5) maintained ACTH at control animal levels, while those of the stress animals were significantly higher. In our model of pretreating animals, before exposure to chronic cold stress, with EA stimulation at $\mathrm{St}_{36}$, we were able to ameliorate the cold stress effects. Furthermore, the pretreatment with $\mathrm{EA} \mathrm{St}_{36}$ maintained CORT at control levels, indicating that EA, specifically at $\mathrm{St}_{36}$, was again effective at preventing the stress-induced increases in both HPA-related hormones in our model of chronic stress. Plasma ACTH levels are under tight negative-feedback control from the glucocorticoids, which are released in response to ACTH secretion. However, during chronic stress, CORT levels remain elevated engendering catabolic consequences that lead to breakdown of vital functions (Sapolsky et al. 2000). As $\mathrm{EA} \mathrm{St}_{36}$ (but not Sham-EA), prevented these stress-induced increases, it is possible that the deleterious effects of chronically high corticosteroids might be prevented in TCM EA-treated animals.

These findings are novel; there are currently no published data on the effects of acupuncture on peripheral ACTH and CORT levels in a chronic stress model such as the one we used. There have, however, been a few studies demonstrating the effects of EA on the HPA in acute stress, but the EA points used were not always specified. Han et al. (1999) discovered that in their rat acute stress model of tooth pulp stimulation, acupuncture had similar effects to those we found on the adrenocortical system. They also found that ACTH and CORT levels were decreased with EA at the large intestine meridian point 4 (LI4, a point commonly used in TCM for facial and dental pain) treatments after tooth pulp stimulation was begun (Han et al. 1999). Their animals had a similar rise in ACTH and CORT with the stressor, which was significantly lower by EA treatments. Interestingly, in another more recent study of the effects of EA on a painful, acute inflammation rat model, the investigators had contradictory findings: CORT levels were elevated by acupuncture treatments, which lead to better outcomes in reduction of inflammation and paw-withdrawal latency (Li et al. 2007). We believe the difference in our model and the aforementioned models may be due to varying pathways that are stimulated during EA procedures, such as to the arcuate nucleus and the periventricular hypothalamic nucleus, depending on the type and duration of stress, as well as the EA point used. Indeed, it is well established that there are various pain/stress ascending pathways, as well as various modulating descending pathways that could have played

Published by Bioscientifica Ltd. 


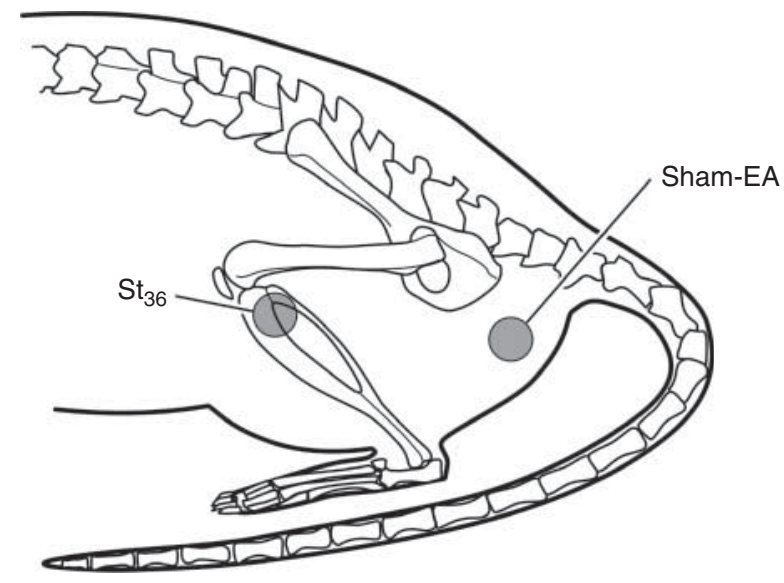

Figure 5

Rat acupuncture point map. The circles mark the sham and acupuncture points $\mathrm{St}_{36}$

a role in acupuncture's specificity in acute vs chronic stress paradigms (Pan et al. 1997, Almeida et al. 2004, Gebhart 2004, Ogata et al. 2005, Saade et al. 2006). Indeed, new theories on stress point to a more specific response depending not only on the stressor but also on the ability of the organism to cope with the stressor and their perceptions, genetics, and environmental factors (Goldstein \& Kopin 2007). Stressor-specific responses have been linked to numerous stressors that have been divided into four varying categories, which include i) physical stress such as cold and pain, such as the one in our model, ii) psychological stress, iii) social stress, and finally iv) homeostatic stressors such as hemorrhage or exercise (Kvetnansky et al. 2009). Stress can be further classified as chronic, as in our model, or acute, and again this may provide an explanation for the difference between our findings and those of the aforementioned study, which had used acute pain/inflammation as their model of stress.

In order to begin examining where in the HPA pathway EA may work, we investigated the central effects of EA St $t_{36}$. Our finding that stimulation at acupoint EA St $\mathrm{t}_{36}$ prevents stress-induced increases in Crh mRNA (Fig. 2) mirrored the efficacy of stimulation on ACTH levels and was consistent with previous work that increased CRH is associated with a variety of stressors (Slawecki et al. 2005, Santibanez et al. 2006, Yanagita et al. 2007). However, currently, there are no reports on the effects of EA on stress-induced elevations of PVN CRH. We believe that as $\mathrm{CRH}$ plays an important role in initiation and integration of the stress response, the central effects of $\mathrm{EA} \mathrm{St}_{36}$ on $\mathrm{CRH}$
PVN may explain the downstream effects we have observed in HPA hormone levels.

In addition to stimulating ACTH, CRH neurons from the PVN project to medullary and spinal cord autonomic neurons (49). Here, they regulate the adrenal and peripheral sympathoneural response to stress (Sawchenko \& Swanson 1982, Swanson et al. 1986). Therefore, we also examined the effects of EA St ${ }_{36}$ on plasma NE and adrenal NPY and TH activity, which are downstream of HP activation. Regulation of $\mathrm{TH}$ expression is a major mechanism by which NE and the adrenergic system respond to stress, and $\mathrm{TH}$ plays an integral role in adaptation to various stressors (Stone \& McCarty 1983). In our model of chronic stress, we found no significant differences in plasma NE (Fig. 1C) or adrenal TH activity (Fig. 4B) between the groups. This finding is actually consistent with the fact that the NE response is primarily an acute effect to help regulate blood pressure and blood flow (Nankova \& Sabban 1999, Nankova et al. 1999). The lack of change in plasma NE and adrenal TH levels in our groups is consistent with other investigators who have found that NE levels, although elevated at first, do indeed stabilize over time with exposure to the same stressor (Glavin 1985a, Glavin 1985b).

Acupuncture has also been used, with some success, in human acute stress models including acute mental stress (Middlekauff et al. 2002). However, there have been no recent studies on the effects of EA on the chronic stressinduced activation of the SNS. As part of the SNS response, stress is also a major activator of adrenal NPY, and various stressors including cold stress have been associated with increases in adrenal Npy mRNA (Renshaw \& Hinson 2001). Our findings support and extend these previous studies, by demonstrating that adrenal Npy mRNA was significantly elevated after 14 days of stress, and $\mathrm{EA} \mathrm{St}_{36}$ prevented this increase in NPY expression. This suggests that NPY may modulate the chronic stress response in concert with the hormones of the HPA. Indeed, the stress-induced increase in adrenal NPY may result from central signals from either CRH or NPY, which we have previously shown to be elevated in the PVN of stressed rats (Eshkevari et al. 2012). In either case, the ability of EA St ${ }_{36}$ to block the increase in adrenal NPY could be via EA actions at the PVN.

We have demonstrated that treatment with EA at the specific point, $\mathrm{St}_{36}$ starting 4 days before, and continuing through 10 days of chronic cold stress, can prevent increases in the central PVN hormone CRH expression, thereby preventing the stress-induced elevations in circulating ACTH and CORT levels. Furthermore, we have shown that peripherally, $\mathrm{EA} \mathrm{St}_{36}$ can influence

Published by Bioscientifica Ltd. 
adrenal NPY levels, which may also contribute to its stressameliorating effects. An important area of future work would be to see if EA is effective when given after stresses have begun, which would have important implications for therapeutic intervention. Further studies will also need to be conducted to identify the potential effects of $\mathrm{EA} \mathrm{St}_{36}$ on the pain pathways activated in this model of chronic cold stress. Additionally, to further confirm our findings, it would be useful to block the pathways elucidated. We have demonstrated that EA St ${ }_{36}$ is useful at reducing stress-induced elevations in HPA hormones. This may be of use therapeutically in stress-related disorders but warrants further investigation, perhaps in a human chronic stress model.

\section{Declaration of interest}

The authors declare that there is no conflict of interest that could be perceived as prejudicing the impartiality of the research reported.

\section{Funding}

The research was funded by the American Association of Nurse Anesthetists (AANA) doctoral fellowship award awarded to $\operatorname{Dr} L \mathrm{E}, \mathrm{PhD}$.

\section{Author contribution statement}

$L E$, a nurse anesthetist, physiologist, and licensed acupuncturist was the main contributing author. The study was conducted based on her experience in treating chronic pain and stress patients; the idea to develop the study was thus generated. She wrote the bulk of the manuscript, with input from contributing authors below. E P, contributed to the set up of the IHC protocols and assisted with the Materials and methods section in the manuscript pertaining to IHC. SE M, provided guidance on study protocols and assisted with manuscript revisions and preparation.

\section{Acknowledgements}

The authors would like to thank the department of histopathology for their assistance with the IHC and Dr Nabil Azzam for his help with identifying the brain regions of interest. The authors would like to thank Dr Lixing Lao for his assistance in setting up our acupuncture protocols and providing us with the rat acupoint map (Li 2003). The authors would also like to thank Mr David Klemm, medical illustrator at Georgetown University, for his redrawing of the rat acupuncture points used in the study.

\section{References}

Almeida TF, Roizenblatt S \& Tufik S 2004 Afferent pain pathways: a neuroanatomical review. Brain Research 1000 40-56. (doi:10.1016/ j.brainres.2003.10.073)

Bernet F, Dedieu JF, Laborie C, Montel V \& Dupouy JP 1998 Circulating neuropeptide $\mathrm{Y}$ (NPY) and catecholamines in rat under resting and stress conditions. Arguments for extra-adrenal origin of NPY, adrenal and extra-adrenal sources of catecholamines. Neuroscience Letters 250 45-48. (doi:10.1016/S0304-3940(98)00454-6)

Cavadas C, Silva AP, Mosimann F, Cotrim MD, Ribeiro CA, Brunner HR \& Grouzmann E 2001 NPY regulates catecholamine secretion from human adrenal chromaffin cells. Journal of Clinical Endocrinology and Metabolism 86 5956-5963. (doi:10.1210/jc.86.12.5956)

Chomczynski P \& Sacchi N 1987 Single-step method of RNA isolation by acid guanidinium thiocyanate-phenol-chloroform extraction. Analytical Biochemistry 162 156-159. (doi:10.1016/0003-2697(87) 90021-2)

Dimitrov EL, DeJoseph MR, Brownfield MS \& Urban JH 2007 Involvement of neuropeptide Y Y1 receptors in the regulation of neuroendocrine corticotropin-releasing hormone neuronal activity. Endocrinology 148 3666-3673. (doi:10.1210/en.2006-1730)

Eshkevari L, Egan R, Phillips D, Tilan J, Carney E, Azzam N, Amri H \& Mulroney SE 2012 Acupuncture at ST36 prevents chronic stressinduced increases in neuropeptide $\mathrm{Y}$ in rat. Experimental Biology and Medicine 237 18-23.

Fung KP, Choa GH, Choy YM, Lee CY, Leung KC, Tsang D, Tso WW \& Wen HL 1980 Effect of electro-acupuncture on behavioral responses and plasma levels of ACTH and TSH in naloxone-induced morphine withdrawal in rats. American Journal of Clinical Nutrition 8 167-169.

Gebhart GF 2004 Descending modulation of pain. Neuroscience and Biobehavioral Reviews 27 729-737. (doi:10.1016/j.neubiorev.2003. 11.008)

Glavin GB 1985a Selective noradrenaline depletion markedly alters stress responses in rats. Life Sciences 37 461-465. (doi:10.1016/ 0024-3205(85)90408-4)

Glavin GB 1985b Stress and brain noradrenaline: a review. Neuroscience and Biobehavioral Reviews 9 233-243. (doi:10.1016/0149-7634(85)90048-X)

Goldstein DS \& Kopin IJ 2007 Evolution of concepts of stress. Stress 10 109-120. (doi:10.1080/10253890701288935)

Han SH, Yoon SH, Cho YW, Kim CJ \& Min BI 1999 Inhibitory effects of electroacupuncture on stress responses evoked by tooth-pulp stimulation in rats. Physiology \& Behavior 66 217-222. (doi:10.1016/ S0031-9384(98)00276-5)

Heilig M 2004 The NPY system in stress, anxiety and depression. Neuropeptides 38 213-224. (doi:10.1016/j.npep.2004.05.002)

Hinson JP, Renshaw D, Cruchley AT \& Kapas S 1998 Regulation of rat adrenal neuropeptide Y (NPY) content: effects of ACTH, dexamethasone and hypophysectomy. Regulatory Peptides 75-76 175-180. (doi:10.1016/S0167-0115(98)00065-2)

Jacobson L 2005 Hypothalamic-pituitary-adrenocortical axis regulation. Endocrinology and Metabolism Clinics of North America 34 271-292, vii. (doi:10.1016/j.ecl.2005.01.003)

Kakui N \& Kitamura K 2007 Direct evidence that stimulation of neuropeptide Y Y5 receptor activates hypothalamo-pituitary-adrenal axis in conscious rats via both corticotropin-releasing factor- and arginine vasopressin-dependent pathway. Endocrinology 148 2854-2862. (doi:10.1210/en.2007-0189)

Kuo LE, Kitlinska JB, Tilan JU, Li L, Baker SB, Johnson MD, Lee EW, Burnett MS, Fricke ST, Kvetnansky R et al. 2007 Neuropeptide Y acts directly in the periphery on fat tissue and mediates stress-induced obesity and metabolic syndrome. Nature Medicine 13 803-811. (doi:10.1038/nm1611)

Kvetnansky R, Sabban EL \& Palkovits M 2009 Catecholaminergic systems in stress: structural and molecular genetic approaches. Physiological Reviews 89 535-606. (doi:10.1152/physrev.00042.2006)

Lao L, Zhang RX, Zhang G, Wang X, Berman BM \& Ren K 2004 A parametric study of electroacupuncture on persistent hyperalgesia and Fos protein expression in rats. Brain Research 1020 18-29. (doi:10.1016/j.brainres. 2004.01.092)

Li Z 2003 In Acupuncture Experimental Science, p 329. China Press of traditonal Chinese medicine: Traditional Chinese Medicine Publisher.

Li C, Chen P \& Smith MS 2000 Corticotropin releasing hormone neurons in the paraventricular nucleus are direct targets for neuropeptide $Y$ 
neurons in the arcuate nucleus: an anterograde tracing study. Brain Research 854 122-129. (doi:10.1016/S0006-8993(99)02324-0)

Li A, Zhang RX, Wang Y, Zhang H, Ren K, Berman BM, Tan M \& Lao L 2007 Corticosterone mediates electroacupuncture-produced anti-edema in a rat model of inflammation. BMC Complementary and Alternative Medicine 7 27. (doi:10.1186/1472-6882-7-27)

Lim S, Ryu YH, Kim ST, Hong MS \& Park HJ 2003 Acupuncture increases neuropeptide Y expression in hippocampus of maternally-separated rats. Neuroscience Letters 343 49-52. (doi:10.1016/S0304-3940 (03)00317-3)

McEwen BS 2012 The ever-changing brain: cellular and molecular mechanisms for the effects of stressful experiences. Developmental Neurobiology 72 878-890. (doi:10.1002/dneu.20968)

McEwen BS, Eiland L, Hunter RG \& Miller MM 2012 Stress and anxiety: structural plasticity and epigenetic regulation as a consequence of stress. Neuropharmacology 62 3-12. (doi:10.1016/j.neuropharm. 2011.07.014)

Middlekauff HR, Hui K, Yu JL, Hamilton MA, Fonarow GC, Moriguchi J, Maclellan WR \& Hage A 2002 Acupuncture inhibits sympathetic activation during mental stress in advanced heart failure patients. Journal of Cardiac Failure 8 399-406. (doi:10.1054/jcaf.2002.129656)

Nankova BB \& Sabban EL 1999 Multiple signalling pathways exist in the stress-triggered regulation of gene expression for catecholamine biosynthetic enzymes and several neuropeptides in the rat adrenal medulla. Acta Physiologica Scandinavica 167 1-9. (doi:10.1046/ j.1365-201x.1999.00566.x)

Nankova B, Kvetnansky R, Hiremagalur B, Sabban B, Rusnak M \& Sabban EL 1996 Immobilization stress elevates gene expression for catecholamine biosynthetic enzymes and some neuropeptides in rat sympathetic ganglia: effects of adrenocorticotropin and glucocorticoids. Endocrinology 137 5597-5604. (doi:10.1210/en.137.12.5597)

Nankova BB, Tank AW \& Sabban EL 1999 Transient or sustained transcriptional activation of the genes encoding rat adrenomedullary catecholamine biosynthetic enzymes by different durations of immobilization stress. Neuroscience 94 803-808. (doi:10.1016/ S0306-4522(99)00290-0)

Ogata A, Sugenoya J, Nishimura N \& Matsumoto T 2005 Low and high frequency acupuncture stimulation inhibits mental stress-induced sweating in humans via different mechanisms. Autonomic Neuroscience: Basic \& Clinical 118 93-101. (doi:10.1016/j.autneu.2004.11.008)

Pan B, Castro-Lopes JM \& Coimbra A 1997 Chemical sensory deafferentation abolishes hypothalamic pituitary activation induced by noxious stimulation or electroacupuncture but only decreases that caused by immobilization stress. A c-fos study. Neuroscience 78 1059-1068. (doi:10.1016/S0306-4522(96)00661-6)

Paxionos G \& Watson C 1998 In The Rat Brain in Stereotactic Coordinates. p 87 Sydney: Academic Press.

Renshaw D \& Hinson JP 2001 Neuropeptide Y and the adrenal gland: a review. Peptides 22 429-438. (doi:10.1016/S0196-9781(01)00353-9)

Renshaw D, Thomson LM, Carroll M, Kapas S \& Hinson JP 2000 Actions of neuropeptide $\mathrm{Y}$ on the rat adrenal cortex. Endocrinology 141 169-173. (doi:10.1210/en.141.1.169)

Saade NE, Al Amin H, Chalouhi S, Baki SA, Jabbur SJ \& Atweh SF 2006 Spinal pathways involved in supraspinal modulation of neuropathic manifestations in rats. Pain 126 280-293. (doi:10.1016/ j.pain.2006.07.010)

Santibanez M, Gysling K \& Forray MI 2006 Desipramine prevents the sustained increase in corticotropin-releasing hormone-like immunoreactivity induced by repeated immobilization stress in the rat central extended amygdala. Journal of Neuroscience Research 84 1270-1281. (doi:10.1002/jnr.21023)
Sapolsky RM, Romero LM \& Munck AU 2000 How do glucocorticoids influence stress responses? Integrating permissive, suppressive, stimulatory, and preparative actions Endocrine Reviews 21 55-89. (doi:10.1210/er.21.1.55)

Sawchenko PE \& Swanson LW 1982 Immunohistochemical identification of neurons in the paraventricular nucleus of the hypothalamus that project to the medulla or to the spinal cord in the rat. Journal of Comparative Neurology 205 260-272. (doi:10.1002/cne.902050306)

Slawecki CJ, Thorsell AK, El Khoury A, Mathe AA \& Ehlers CL 2005 Increased CRF-like and NPY-like immunoreactivity in adult rats exposed to nicotine during adolescence: relation to anxiety-like and depressive-like behavior. Neuropeptides 39 369-377. (doi:10.1016/ j.npep.2005.06.002)

Stone EA \& McCarty R 1983 Adaptation to stress: tyrosine hydroxylase activity and catecholamine release. Neuroscience and Biobehavioral Reviews 7 29-34. (doi:10.1016/0149-7634(83)90005-2)

Suda T, Tozawa F, Iwai I, Sato Y, Sumitomo T, Nakano Y, Yamada M \& Demura H 1993 Neuropeptide Y increases the corticotropin-releasing factor messenger ribonucleic acid level in the rat hypothalamus. Brain Research. Molecular Brain Research 18 311-315. (doi:10.1016/0169-328X (93)90094-6)

Sun JP, Pei HT, Jin XL, Yin L, Tian QH \& Tian SJ 2005 Effects of acupuncturing Tsusanli (ST36) on expression of nitric oxide synthase in hypothalamus and adrenal gland in rats with cold stress ulcer. World Journal of Gastroenterology 11 4962-4966.

Swanson LW, Sawchenko PE \& Lind RW 1986 Regulation of multiple peptides in CRF parvocellular neurosecretory neurons: implications for the stress response. Progress in Brain Research 68 169-190.

Szczepanska-Sadowska E, Cudnoch-Jedrzejewska A, Ufnal M \& Zera T 2010 Brain and cardiovascular diseases: common neurogenic background of cardiovascular, metabolic and inflammatory diseases. Journal of Physiology and Pharmacology 61 509-521.

Tamashiro KL 2011 Metabolic syndrome: links to social stress and socioeconomic status. Annals of the New York Academy of Sciences $123146-55$.

Tamashiro KL, Sakai RR, Shively CA, Karatsoreos IN \& Reagan LP 2011 Chronic stress, metabolism, and metabolic syndrome. Stress 14 468-474. (doi:10.3109/10253890.2011.606341)

Tran TT, Srivareerat M \& Alkadhi KA 2011 Chronic psychosocial stress accelerates impairment of long-term memory and late-phase long-term potentiation in an at-risk model of Alzheimer's disease. Hippocampus 21 724-732. (doi:10.1002/hipo.20790)

Wen HL, Ho WK, Wong HK, Mehal ZD, Ng YH \& Ma L 1978 Reduction of adrenocorticotropic hormone (ACTH) and cortisol in drug addicts treated by acupuncture and electrical stimulation (AES). Comparative Medicine East and West 6 61-66.

Yanagita S, Amemiya S, Suzuki S \& Kita I 2007 Effects of spontaneous and forced running on activation of hypothalamic corticotropin-releasing hormone neurons in rats. Life Sciences 80 356-363. (doi:10.1016/j.lfs. 2006.09.027)

Yang CH, Lee BB, Jung HS, Shim I, Roh PU \& Golden GT 2002 Effect of electroacupuncture on response to immobilization stress. Pharmacology, Biochemistry, and Behavior 72 847-855. (doi:10.1016/S00913057(02)00769-4)

Zhang RX, Lao L, Wang X, Fan A, Wang L, Ren K \& Berman BM 2005 Electroacupuncture attenuates inflammation in a rat model. Journal of Alternative and Complementary Medicine 11 135-142. (doi:10.1089/ acm.2005.11.135)

Zukowska-Grojec Z 1995 Neuropeptide Y. A novel sympathetic stress hormone and more. Annals of the New York Academy of Sciences 771 219-233. (doi:10.1111/j.1749-6632.1995.tb44683.x)

Received in final form 30 January 2013

Accepted 4 February 2013

Accepted Preprint published online 4 February 2013 http://joe.endocrinology-journals.org DOI: 10.1530/JOE-12-0404
() 2013 Society for Endocrinology Printed in Great Britain 